\title{
Detection of tissue factor in platelets: why is it so troublesome?
}

${\text { Bjarne } \emptyset_{\text {sterud }}^{\mathrm{a}} \text { and Beth A. Bouchard }}^{\mathrm{b} *}$

${ }^{a}$ K.G. Jebsen Thrombosis Research Center (TREC), Deparment of Medical Biology, UiT The Artic University of Norway, Troms $\phi$, Norway; ${ }^{b}$ Department of Biochemistry, Larner College of Medicine at the University of Vermont, Burlington, VT, USA

* beth.bouchard@med.uvm.edu 


\section{Detection of tissue factor in platelets: why is it so troublesome?}

Tissue factor (TF) is the most important trigger for the extrinsic coagulation pathway. TF, earlier denoted as thromboplastin, has always been a mystery since its discovery due to its abundant presence in most human tissues but not blood. The latter has been extensively studied in a vast quest for possible sources of blood-borne TF yielding many conflicting findings and confusing conclusions regarding the presence of TF mRNA, protein or functional procoagulant activity in virtually all blood cells. Platelets, in particular, have been heavily scrutinized by investigators eager to demonstrate expression of TF. However, some investigators including our own groups have not found evidence for TF in platelets. This article discusses notable reports and possible reasons for erroneous detection of platelet TF antigen and activity including artificially hyperstimulated platelets, suboptimal purity of cell preparations, flaws in study design or choice of reagents.

Keywords: coagulation; megakaryocyte; platelet; tissue factor

\section{Introduction}

Blood clotting is governed by a finely tuned system composed of cells, proteins, phospholipids and calcium $(\mathrm{Ca})$ ions. Damage to a blood vessel triggers this system through exposure of tissue factor (TF) to the blood. In the initiation phase, TF serves as a cellular receptor and cofactor for plasma FVII/FVIIa in the early event of FX and FIX activation in the presence of phospholipids [1]. Once trace amounts of FXa have been formed, it interacts with phosphatidylserine (PS) on collagen-activated platelets and FV/FVa released from platelet $\alpha$-granules. An interaction of FXa with FVa and PS forms the prothrombinase complex, which cleaves prothrombin (FII) and results in thrombin (FIIa) generation [2]. FXa also activates additional platelet-derived FV to FVa $[3,4]$. The initial generation of minute amounts of thrombin is essential for further feedback activation of plasma-derived FVIII and FV [5], platelets [6] and ultimately FXI [7].

The major wave of thrombin generation following the initiation event is not associated with the TF-bearing cells, due to an almost instant shut down of the TF-dependent pathway by tissue factor pathway inhibitor (TFPI) [8]. As soon as FXa has been generated, a quaternary complex of TF-FVIIa-TFPI-Xa is formed whereby TF-FVIIa is inactivated. The activation of 
FVIII and FV by thrombin results in more efficient FXa formation and subsequently more thrombin, which in turn activates FXI in the presence of activated platelets [7, 9] in a reaction shown to be accelerated by short chain polyphosphates similar to those derived from platelets [9]. These reactions lead to a burst of thrombin and formation of fibrin.

\section{Blood-borne TF and platelet TF?}

\section{Reports of TF expression in platelets}

The events described above lead to formation of a stable fibrin clot at sites of vascular injury during normal hemostasis. In contrast, the events leading to thrombosis are more complex, and TF present in the intravascular space has been anticipated to play an important role. However, using CAT and PPL assays it has become more and more evident that it is PS rather than TF that is the driving force in thrombosis whereas TF appears to be essential in the initiation of the coagulation system and is then turned off by TFPI-FVIIa-TF-Xa complex formation (Osterud, unpublished observations).

In 1999 it was suggested that active TF was present in circulating blood, which was named blood-borne TF [10]. The basis for this assumption was the observation that when whole blood of healthy individuals is allowed to pass along a collagen-coated glass slide or over pig arterial media ex vivo, a TF-dependent thrombosis is formed [10]. In a follow-up study, it was shown that monocytes and possibly polymorphonuclear leukocytes might be involved in the transfer of TF to platelets [11]. Thus, the origin of the blood-borne TF appeared to be leukocytes expressing TF. In contrast, Zillman et al. [12] proposed the presence of TF on circulating platelets. In this study, TF antigen and activity appeared on platelets adhering to leukocytes after a five minute stimulation of whole blood with collagen. An extension of this study revealed TF activity exposed on platelet membranes after activation of platelets with either collagen or thrombin [13]. TF was found to be stored within the $\alpha$-granules and the open canalicular system of platelets. Siddiqui and colleagues also found the presence of TF antigen on both resting and activated platelets [14]. TF associated with the platelet surface was biologically inactive and it was claimed that platelets contain an inactive form of TF that may develop functional activity following its release and expression. 
Another study adding to the controversy of the presence, synthesis and functional activity of $\mathrm{TF}$ in platelets was the report that $\mathrm{TF}$ is present in quiescent platelets and upregulated by thrombin receptor-activating peptide activation [15]. New biosynthesis of TF in resting and activated platelets was also reported. Later the same research group proposed that only von Willebrand factor in combination with ristocetin rapidly induces TF activity in platelets, and that cell membranes needed to be intact (not lysed) in order to detect TF activity [16]. Curiously, the TF activity appeared to be independent of added FVII and was not affected by an anti-TFPI antibody.

Consistent with the above observations, Camera and coworkers in several reports [17-19] claimed the presence of functionally active, membrane-associated and immune-reactive TF in activated platelets of healthy individuals, and detectable TF mRNA in non-stimulated platelets. More recently, the same group reported that functionally active TF is expressed by human megakaryocytes and then transferred to a subset of shed platelets [20]. Both TF pre-mRNA and mature mRNA were identified in the shed platelets. TF pre-mRNA in platelets was reported for the first time by Schwertz et al. in 2006, but it remains unclear whether it plays any role in normal physiology or pathophysiology [21].

\section{Lack of TF expression in platelets}

In contrast to the numerous reports of expression of TF antigen and/or activity in quiescent or activated platelets, several studies by Butenas and Mann [22-25] and Osterud and colleagues [26, 27] were unable to detect TF antigen or activity even after prolonged platelet stimulation using well-characterized antibodies and activity assays. Likewise, no TF mRNA was present in human or mouse platelets using RNA-seq [28].

\section{Transfer of TF to platelets}

Other observations suggest that platelet-associated TF originates from extravascular vesicles (EVs) derived from activated monocytes or TF-expressing tumor cells [27, 29, 30]. In a study by del Conde, shed EVs from activated monocytes bound and fused to activated platelets, transferring both protein and lipid to the platelet membrane [29]. This interaction between EVderived $\mathrm{TF}$ and activated platelets was blocked by either annexin $\mathrm{V}$ or an antibody to P-selectin 
glycoprotein ligand-1 (PSGL-1) pointing to a PS-dependent, P-selectin-mediated interaction. The role of activated platelets in the regulation of TF expression and activity in monocytes is well-studied, and mediated through interactions between monocytes, platelets and neutrophils in a P-selectin-PSGL-1 dependent reaction [31].

\section{How can the discrepancy of TF detection in platelets be explained?}

In our opinion, the conflicting results regarding the presence or absence of TF in platelets can be explained by: 1) contamination of platelet preparations with monocytes, 2) non-specific $\mathrm{TF}$ antibodies, and/or 3) TF activity assays lacking both sensitivity and specificity.

\section{Platelet preparation}

In a recent study showing the presence of substantial amounts of TF in both resting and activated platelets, the authors discuss the controversy around TF expression in platelets due to methodological differences in platelet isolation [32]. The authors argue that only large platelets express functionally active TF antigen, whereas TF activity in small platelets is quenched by TFPI and therefore undetectable. They highlight the importance of using lower centrifugal forces

for platelet-rich plasma preparation to separate the platelets from the monocyte-containing buffy coat, and the use of the lower fractions of platelet-rich plasma preparations, which contain the larger platelets. However, since the larger platelets are juxtaposed with the buffy coat this could lead to possible contamination of platelets by monocytes that contain TF antigen/activity and mRNA. Given the high sensitivity of PCR-based and TF activity detection methods, small amounts of contaminating monocytes may give rise to substantial TF mRNA and activity levels in platelet preparations. In addition, monocyte contamination may also give rise to TF-bearing EVs when the platelet preparations are subjected to activation. These EVs may subsequently fuse with platelets yielding detection of TF antigen on the platelet surface by ELISA or flow cytometry. Although the platelet preparations in this study contained less than 5 leukocytes $/ 10^{5}$ platelets, attempts to remove remaining monocytes to avoid detection of counterfeit activity by monocyte-derived TF is crucial. Contaminating monocytes can be removed using microbeads coupled to anti-CD14 antibody, but most studies in this field have failed to do this [26]. 


\section{Flow cytometric analysis}

Many studies utilizing flow cytometric analysis show the presence of TF antigen in both resting and activated platelets. These findings cannot be explained solely by monocyte contamination of platelet preparations.

Conflicting reports showing TF platelet positivity, apart from differences due to isolation procedures, could partially be explained by the choice of anti-TF antibody and/or the antibody concentrations utilized for flow cytometry. It is well recognized that at high concentrations some antibodies bind cells non-specifically. Using flow cytometry, CLB/TF-5 and VIC7 anti-TF antibody clones appeared to bind and detect large amounts of TF in resting and activated platelets, as well as in non-stimulated monocytes and EVs isolated from the platelet-free plasma of healthy individuals [33]. A clear dose-dependent but non-specific binding to resting platelets was observed with these two clones. Although a third anti-TF antibody, VD8, showed no binding to resting platelets, there was a significant increase in binding to $\mathrm{Ca}$ ionophorestimulated platelets, but to a much lesser extent than VIC7 and CLB/TF-5. As Ca ionophorestimulated platelets and EVs from platelet-free plasma or LPS-stimulated monocytes are characterized by a high exposure of PS on the surface, one may question the specificity of VIC7, CLB/TF-5 and VD8 antibodies and consider that they cross-react with cell membrane PS [33].

In another study, it was concluded that the total expression of TF on platelets was more than 1000-fold higher than that on monocytes per microliter of blood [34]. This study relied on the usage of an anti-TF antibody later proven to be highly non-specific [33]. Given this observation to be correct, one may further speculate that severe thrombosis would have progressed under conditions when platelets are activated in vivo.

\section{TF Western blot}

Western blotting is another method frequently used for detection of TF antigen in cells. Some studies show TF protein band as a wide band $[35,36]$ at just below $50 \mathrm{kDa}$ consistent with its variable degree of glycosylation $[37,38]$, whereas other investigators claim TF protein is a narrow band in the same region $[15,39,40]$. One may speculate that the discrepancy in findings can be explained by non-specific binding of the secondary antibodies in the absence of appropriate controls. One may also anticipate that the narrow band at $50 \mathrm{kDa}$ is the heavy chain of $\mathrm{IgG}$, which appears as a much narrower band than TF protein. Use of highly specific 
antibodies at lower concentrations as well as relevant controls can restrict these speculative findings.

\section{TF activity measurements}

It is widely accepted that TF activity in plasma of healthy individuals is so negligible that it will never lead to a pathological activation of thrombosis [41]. However, measurements of TF activity in patients' plasmas have been more variable [41,42] suggesting that the assays used in these studies need closer inspection.

Since TF is a cofactor for FVIIa in the activation of FX, the most frequent assay used in TF activity measurements is based on the proteolytic cleavage of FX to FXa followed by the quantification of FXa by chromogenic substrate. Unfortunately, this assay requires a long incubation time (60-120 minutes) as the catalytic conversion of the substrate is slow. In addition, TF-independent activation of FX may take place. One alternative reaction is the activation of FX by FVIIa in the presence of PS exposed on the cell surface [43-45]. Although this reaction is relatively slow, it is capable of generating substantial amounts of FXa. Any FXa formed will greatly amplify the activation of more FX to FXa through its interaction with PS [46]. Thus, only a minor part of the measured FXa may be due to TF. Another aspect of this assay is the requirement of PS for the activation of FX by the enzyme complex TF/FVIIa, where increasing amounts of PS may amplify the activity of trace amounts of TF. Although TF may be required, as perceived by its neutralization by anti-TF antibodies, the FXa formed may represent autoactivated FX [46]. Thus, the FXa-based assays are neither sensitive nor specific for detection of TF activity in cells/EVs due to the inevitable presence of membranes rich in PS. The availability of PS is a stringent limiting factor of the assay, whereby activated platelets may falsely provide PS as a cofactor in the assay rather than high TF activity. Indeed studies using anti-TF antibodies to neutralize expression of high TF activity in platelets [15] or eosinophils [39, 40] may simply reflect inhibition of trace amounts of TF during the initial phase of FX activation preventing further activation of FX by FXa independent of TF in later stages.

It can be speculated that TF activity assays based on recalcification of plasma are nonspecific given the large content of PS in the test samples, which appears to be a limiting factor of the assay. This is not only relevant for recalcification of plasma and measurement of clotting time, but also for the CAT assays based on quantification of thrombin in a plasma system [47]. 
While the partial attenuation of thrombin generation by anti-TF antibodies has been interpreted as evidence of the presence of high amounts of TF, the high activity more likely reflects availability of substantial amounts of PS rather than trace amounts of TF. In the presence of inhibitors of FXIIa, such as CTI, non-TF-dependent activation pathways are still not blocked because when traces of FXa are generated by tiny amounts of TF, the presence of FVa and PS in the system will produce more FVIIa and, thus, will amplify the activity of the TF.

Studies have also demonstrated that a commercially available TF activity kit, ACTICHROME $^{\circledR}$ (Sekisui Diagnostics), frequently used for detection of TF in patient plasma samples is non-specific. Bogdanov and colleagues assessed the presence of TF in plasma of healthy controls and subsets of patients using an in-house, well-characterized assay and ACTICHROME $^{\circledR}$ [42]. High levels of TF were detected in patients with coronary artery disease as compared to controls using ACTICHROME ${ }^{\circledR}$. Additional analyses indicated that the FXa activity measured using ACTICHROME ${ }^{\circledR}$ occurred independent of added FVIIa and TF [42]. Furthermore, there was an inverse correlation between the two assays.

\section{ELISA assays}

ELISA has most often been regarded as a specific assay for the measurement of TF protein concentrations, and many monoclonal and polyclonal antibodies for these assays have been raised against various TF epitopes. However, the specificity, selectivity and affinity of these commercially available antibodies should be questioned.

In recent studies by Cohen et al. [48], two different commercial TF ELISA kits failed to detect differences in EV-associated TF and soluble TF antigens in platelet-poor plasma obtained from patients with ovarian cancer compared to healthy subjects [48]. Interestingly, TF antigen measured in plasma obtained from ovarian cancer patients before and after ultracentrifugation remained essentially unchanged. As significant TF procoagulant activity was measured in EVs isolated from the plasma of the same patients, it can be concluded that TF antigen and TF procoagulant activity measured in EVs are not correlated. One of these commercially available ELISA kits also failed to show the correlation of TF concentration in plasma of patients with venous thrombosis and the likelihood of having venous thrombosis [49, 50]. Thus, the question of whether TF antigen measured with ELISA can be truly correlated with TF activity in plasma of patients with hypercoagulability is still unknown. The major failure to see any correlation may 
be caused by the cross-reactivity of TF antibodies with alternatively-spliced (soluble) TF present in plasma, as this form of TF does not possess any procoagulant activity in the absence of phospholipids [51, 52].

\section{TF in megakaryocytes?}

In the studies by Zillman and colleagues [12] described above ("Reports of TF expression in platelets"), isolated bone marrow megakaryocytes were shown to have TF antigen values below the detection limit of the assay. In addition, no TF mRNA was detected in these cells. In contrast to this report, TF pre-mRNA, mRNA and active protein were identified in the megakaryoblastic cell line (Meg-01), although the authors claim that similar results were obtained using megakaryocytes derived from $\mathrm{CD} 34^{+}$cells [20]. It was further demonstrated that functionally active TF antigen, its pre-mRNA and full length TF mRNA were transferred to a subset of shed platelets. However, caution should be taken when interpreting these results, as various transformed cells are known to express TF [53-56]. Thus, the same cell type in vivo or freshly isolated ex vivo (i.e. bone marrow-derived megakaryocytes [12]) in a non-transformed state may actually fail to synthetize functionally active TF antigen.

\section{Transfer of TF from cells expressing TF to other cells than platelets}

There have also been reports of TF expression by neutrophils and eosinophils [39, 40, 57, 58]. Interestingly, a lack of TF mRNA was observed in a mouse model when clusters of TF-positive cells detected in the spleen were predominantly granulocytes [57]. Based on this observation and the presence of TF-positive granulocytes detected after splenectomy, it was hypothesized that granulocytes take up TF for transport to other locations.

Further evidence for lack of TF expression in neutrophils was obtained by the use of

small interfering RNA and overexpressed TF fluorescent protein fusion in human monocytes and granulocytes isolated by immunoaffinity [59]. The use of this approach demonstrated a direct transfer of TF from activated monocytes to granulocytes in whole blood. Similarly, isolated eosinophils possessed no TF mRNA in resting or activated cells [60], contrary to other reports [39].

These reports further underscore the issues surrounding the assays and reagents available for detection of TF as discussed above. But it is important to emphasize that under pathological 
conditions TF-rich EVs derived from monocytes and tumor cells may play an important role in thrombosis.

\section{Conclusions and future considerations}

It is our opinion that studies using well-characterized reagents and employing well-controlled immune and functional assays do not show either TF activity or TF antigen in platelets. In order to develop a specific TF activity test, one has to consider why the current assays are non-specific. A major problem in the most used TF activity assay is the slow cleavage of the chromogenic/fluorescence substrates for FXa, making it necessary to incubate the test sample with FVIIa and FX for at least $60 \mathrm{~min}$. Since there are simultaneous FX activation reactions independent of TF going on, including reactions that are not blocked by anti-TF antibodies, artificial high TF activity values are obtained, even when there may not be any TF present or only trace amounts. To make the system more sensitive, the generated FXa activity in the incubation mixture, has to be amplified by including prothrombin, FVa and phospholipids followed by the measurement of thrombin with a chromogenic substrate. As a result, the incubation time is reduced to 3-4 min minimizing the contributions of the TF-independent reactions to close to zero. One of the authors (В.Ø.) has used such an assay for more than 30 years, and we believe this to be the most specific and reliable assay for measuring TF activity [61].

We believe that in vivo TF may be associated with platelets by a direct transfer of TF from TF-producing cells. Activated platelets and platelet-derived EVs are extremely procoagulant independent of the presence of TF due their expression of PS on their membranes. In contrast to the rapid inactivation of TF by its inhibitor, TFPI, PS is functioning as a very stable template and cofactor for the enzyme complexes tenase, prothrombinase and the single enzymes such as FXa, FVIIa, and thrombin in the activation of FXI. Not surprisingly, activated platelets are strongly associated with arterial thrombosis as well as venous thromboembolism.

\section{Declaration of Interest}

The authors report no conflicts of interest.

\section{References}


[1] Komiyama Y, Pedersen AH, Kisiel W. Proteolytic activation of human factors IX and X by recombinant human factor VIla: effects of calcium, phospholipids, and tissue factor. Biochemistry 1990; 29: 9418-9425.

[2] Kalafatis M, Swords NA, Rand MD, Mann KG. Membrane-dependent reactions in blood coagulation: role of the vitamin K-dependent enzyme complexes. Biochim Biophys Acta 1994; 1227: 113129.

[3] Monkovic DD, Tracy PB. Functional characterization of human platelet-released factor $V$ and its activation by factor Xa and thrombin. J Biol Chem 1990; 265: 17132-17140.

[4] Schuijt TJ, Bakhtiari K, Daffre S, DePonte K, Wielders SJH, Marquart JA, Hovius JW, van der Poll T, Fikrig E, Bunce MW, Camire RM, Nicolaes GAF, Meijers JCM, van 't Veer C. Factor Xa activation of factor $V$ is of paramount importance in initiating the coagulation system: lessons from a tick salivary protein. Circulation 2013; 128: 254-266.

[5] Pieters J, Lindhout T, Hemker HC. In situ-generated thrombin is the only enzyme that effectively activates factor VIII and factor V in thromboplastin-activated plasma. Blood 1989; 74: 1021-1024.

[6] De Candia E. Mechanisms of platelet activation by thrombin: a short history. Thromb Res 2012; 129: $250-256$.

[7] Gailani D, Broze GJ, Jr. Factor XI activation in a revised model of blood coagulation. Science 1991; 253: 909-912.

[8] Baugh RJ, Broze GJ, Jr., Krishnaswamy S. Regulation of extrinsic pathway factor Xa formation by tissue factor pathway inhibitor. J Biol Chem 1998; 273: 4378-4386.

[9] Choi SH, Smith SA, Morrissey JH. Polyphosphate is a cofactor for the activation of factor XI by thrombin. Blood 2011; 118: 6963-6970.

[10] Giesen PL, Rauch U, Bohrmann B, Kling D, Roque M, Fallon JT, Badimon JJ, Himber J, Riederer MA, Nemerson Y. Blood-borne tissue factor: another view of thrombosis. Proc Natl Acad Sci U S A 1999; 96: 2311-2315.

[11] Rauch U, Bonderman D, Bohrmann B, Badimon JJ, Himber J, Riederer MA, Nemerson Y. Transfer of tissue factor from leukocytes to platelets is mediated by CD15 and tissue factor. Blood 2000; 96: 170175.

[12] Zillmann A, Luther T, Muller I, Kotzsch M, Spannagl M, Kauke T, Oelschlagel U, Zahler S, Engelmann B. Platelet-associated tissue factor contributes to the collagen-triggered activation of blood coagulation. Biochem Biophys Res Commun 2001; 281: 603-609.

[13] Muller I, Klocke A, Alex M, Kotzsch M, Luther T, Morgenstern E, Zieseniss S, Zahler S, Preissner K, Engelmann B. Intravascular tissue factor initiates coagulation via circulating microvesicles and platelets. FASEB J 2003; 17: 476-478.

[14] Siddiqui FA, Desai H, Amirkhosravi A, Amaya M, Francis JL. The presence and release of tissue factor from human platelets. Platelets 2002; 13: 247-253.

[15] Panes O, Matus V, Saez CG, Quiroga T, Pereira J, Mezzano D. Human platelets synthesize and express functional tissue factor. Blood 2007; 109: 5242-5250.

[16] Mezzano DP, O. Regulation of platelet-expressed tissue factor. J Thromb Haemost 2009; Suppl. 2: AS-MO-041.

[17] Camera M, Frigerio M, Toschi V, Brambilla M, Rossi F, Cottell DC, Maderna P, Parolari A, Bonzi R, De Vincenti O, Tremoli E. Platelet activation induces cell-surface immunoreactive tissue factor expression, which is modulated differently by antiplatelet drugs. Arterioscler Thromb Vasc Biol 2003; 23: 1690-1696.

[18] Camera M, Brambilla M, Boselli D, Facchinetti L, Canzano P, Rossetti L, Toschi V, Tremoli E. Response: functionally active platelets do express tissue factor. Blood 2012; 119: 4339-4341.

[19] Camera M, Brambilla M, Toschi V, Tremoli E. Tissue factor expression on platelets is a dynamic event. Blood 2010; 116: 5076-5077. 
[20] Brambilla M, Facchinetti L, Canzano P, Rossetti L, Ferri N, Balduini A, Abbonante V, Boselli D, De Marco L, Di Minno MN, Toschi V, Corsini A, Tremoli E, Camera M. Human megakaryocytes confer tissue factor to a subset of shed platelets to stimulate thrombin generation. Thromb Haemost 2015; 114: 579592.

[21] Schwertz H, Tolley ND, Foulks JM, Denis MM, Risenmay BW, Buerke M, Tilley RE, Rondina MT, Harris EM, Kraiss LW, Mackman N, Zimmerman GA, Weyrich AS. Signal-dependent splicing of tissue factor pre-mRNA modulates the thrombogenicity of human platelets. J Exp Med 2006; 203: 2433-2440.

[22] Bouchard BA, Krudysz-Amblo J, Butenas S. Platelet tissue factor is not expressed transiently after platelet activation. Blood 2012; 119: 4338-4339; author reply 4339-4341.

[23] Bouchard BA, Mann KG, Butenas S. No evidence for tissue factor on platelets. Blood 2010; 116: 854-855.

[24] Butenas S, Bouchard BA, Brummel-Ziedins KE, Parhami-Seren B, Mann KG. Tissue factor activity in whole blood. Blood 2005; 105: 2764-2770.

[25] Bouchard BA, Gissel MT, Whelihan MF, Mann KG, Butenas S. Platelets do not express the oxidized or reduced forms of tissue factor. Biochim Biophys Acta 2014; 1840: 1188-1193.

[26] Osterud B, Olsen JO. Human platelets do not express tissue factor. Thromb Res 2013; 132: 112-

115.

[27] Breimo ES, Osterud B. Generation of tissue factor-rich microparticles in an ex vivo whole blood model. Blood Coagul Fibrinolysis 2005; 16: 399-405.

[28] Rowley JW, Oler AJ, Tolley ND, Hunter BN, Low EN, Nix DA, Yost CC, Zimmerman GA, Weyrich AS. Genome-wide RNA-seq analysis of human and mouse platelet transcriptomes. Blood 2011; 118: e101-111.

[29] Del Conde I, Shrimpton CN, Thiagarajan P, Lopez JA. Tissue-factor-bearing microvesicles arise from lipid rafts and fuse with activated platelets to initiate coagulation. Blood 2005; 106: 1604-1611. [30] Kleinjan A, Boing AN, Sturk A, Nieuwland R. Microparticles in vascular disorders: how tissue factor-exposing vesicles contribute to pathology and physiology. Thromb Res 2012; 130 Suppl 1: S71-73.

[31] Halvorsen H, Olsen JO, Osterud B. Granulocytes enhance LPS-induced tissue factor activity in monocytes via an interaction with platelets. J Leukoc Biol 1993; 54: 275-282.

[32] Brambilla M, Rossetti L, Zara C, Canzano P, Giesen PLA, Tremoli E, Camera M. Do methodological differences account for the current controversy on tissue factor expression in platelets? Platelets 2018; 29: 406-414.

[33] Basavaraj MG, Olsen JO, Osterud B, Hansen JB. Differential ability of tissue factor antibody clones on detection of tissue factor in blood cells and microparticles. Thromb Res 2012; 130: 538-546. [34] Brambilla M, Camera M, Colnago D, Marenzi G, De Metrio M, Giesen PL, Balduini A, Veglia F, Gertow K, Biglioli P, Tremoli E. Tissue factor in patients with acute coronary syndromes: expression in platelets, leukocytes, and platelet-leukocyte aggregates. Arterioscler Thromb Vasc Biol 2008; 28: 947953.

[35] Brisseau GF, Dackiw AP, Cheung PY, Christie N, Rotstein OD. Posttranscriptional regulation of macrophage tissue factor expression by antioxidants. Blood 1995; 85: 1025-1035.

[36] Osterud B, Rao LV, Olsen JO. Induction of tissue factor expression in whole blood: lack of evidence for the presence of tissue factor expression in granulocytes. Thromb Haemost 2000; 83: 861867.

[37] Krudysz-Amblo J, Jennings ME, 2nd, Mann KG, Butenas S. Carbohydrates and activity of natural and recombinant tissue factor. J Biol Chem 2010; 285: 3371-3382.

[38] Krudysz-Amblo J, Jennings ME, 2nd, Matthews DE, Mann KG, Butenas S. Differences in the fractional abundances of carbohydrates of natural and recombinant human tissue factor. Biochim Biophys Acta 2011; 1810: 398-405. 
[39] Moosbauer C, Morgenstern E, Cuvelier SL, Manukyan D, Bidzhekov K, Albrecht S, Lohse P, Patel $K D$, Engelmann B. Eosinophils are a major intravascular location for tissue factor storage and exposure. Blood 2007; 109: 995-1002.

[40] Uderhardt S, Ackermann JA, Fillep T, Hammond VJ, Willeit J, Santer P, Mayr M, Biburger M, Miller M, Zellner KR, Stark K, Zarbock A, Rossaint J, Schubert I, Mielenz D, Dietel B, Raaz-Schrauder D, Ay C, Gremmel T, Thaler J, Heim C, Herrmann M, Collins PW, Schabbauer G, Mackman N, Voehringer D, Nadler JL, Lee JJ, Massberg S, Rauh M, Kiechl S, Schett G, O'Donnell VB, Kronke G. Enzymatic lipid oxidation by eosinophils propagates coagulation, hemostasis, and thrombotic disease. J Exp Med 2017; 214: 2121-2138.

[41] Butenas S, Orfeo T, Mann KG. Tissue factor in coagulation: Which? Where? When? Arterioscler Thromb Vasc Biol 2009; 29: 1989-1996.

[42] Bogdanov VY, Cimmino G, Tardos JG, Tunstead JR, Badimon JJ. Assessment of plasma tissue factor activity in patients presenting with coronary artery disease: limitations of a commercial assay. J Thromb Haemost 2009; 7: 894-897.

[43] Osterud B. How to measure factor VII and factor VII activation. Haemostasis 1983; 13: 161-168.

[44] Telgt DS, Macik BG, McCord DM, Monroe DM, Roberts HR. Mechanism by which recombinant factor VIla shortens the aPTT: activation of factor X in the absence of tissue factor. Thromb Res 1989; 56 : 603-609.

[45] Rao LV, Rapaport SI. Factor VIla-catalyzed activation of factor X independent of tissue factor: its possible significance for control of hemophilic bleeding by infused factor VIla. Blood 1990; 75: 10691073.

[46] Jesty J, Spencer AK, Nemerson Y. The mechanism of activation of factor X. Kinetic control of alternative pathways leading to the formation of activated factor X. J Biol Chem 1974; 249: 5614-5622. [47] Hemker HC, Giesen P, R. AD, Regnault V, de Smedt E, Wagenvoord R, Lecompte T, Beguin S. Calibrated automated thrombin generation measurement in clotting plasma. Pathophysiol Haemost Thromb 2003; 33: 4-15.

[48] Cohen JG, Prendergast E, Geddings JE, Walts AE, Agadjanian H, Hisada Y, Karlan BY, Mackman N, Walsh CS. Evaluation of venous thrombosis and tissue factor in epithelial ovarian cancer. Gynecol Oncol 2017; 146: 146-152.

[49] Hernandez C, Orbe J, Roncal C, Alvarez-Hernandez M, Martinez de Lizarrondo S, Alves MT, Garcia Mata J, Paramo JA. Tissue factor expressed by microparticles is associated with mortality but not with thrombosis in cancer patients. Thromb Haemost 2013; 110: 598-608.

[50] Hunt BJ, Parmar K, Horspool K, Shephard N, Nelson-Piercy C, Goodacre S, Di PEPrg. The DiPEP (Diagnosis of PE in Pregnancy) biomarker study: An observational cohort study augmented with additional cases to determine the diagnostic utility of biomarkers for suspected venous thromboembolism during pregnancy and puerperium. Br J Haematol 2018; 180: 694-704.

[51] Censarek P, Bobbe A, Grandoch M, Schror K, Weber AA. Alternatively spliced human tissue factor (asHTF) is not pro-coagulant. Thromb Haemost 2007; 97: 11-14.

[52] Unlu B, Bogdanov VY, Versteeg HH. Interplay betwwen alternatively spliced tissue factor and full length tissue factor in modulating coagulant activity of endothelial cells. Thromb Res 2017; 156: 1-7.

[53] Versteeg HH. Tissue Factor: Old and New Links with Cancer Biology. Semin Thromb Hemost 2015; 41: 747-755.

[54] Cole M, Bromberg M. Tissue factor as a novel target for treatment of breast cancer. The Oncologist 2013; 18: 14-18.

[55] Ruf W, Disse J, Correa Carneiro-Lobo T, Yokota N, Schaffner F. Tissue factor and cell signalling in cancer progression and thrombosis. J Thromb Haemost 2011; 9: 306-315.

[56] Carson SD, Pirruccello SJ. Tissue factor and cell morphology variations in cell lines subcloned from U87-MG. Blood Coagul Fibrinolysis 1998; 9: 539-547. 
[57] de Waard V, Hansen HR, Spronk HH, Timmerman JJ, Pannekoek H, Florquin S, Reitsma PH, ten Cate $\mathrm{H}$. Differential expression of tissue factor mRNA and protein expression in murine sepsis. The role of the granulocyte revisited. Thromb Haemost 2006; 95: 348-353.

[58] Maugeri N, Manfredi AA. Tissue Factor Expressed by Neutrophils: Another Piece in the Vascular Inflammation Puzzle. Semin Thromb Hemost 2015; 41: 728-736.

[59] Egorina EM, Sovershaev MA, Olsen JO, Osterud B. Granulocytes do not express but acquire monocyte-derived tissue factor in whole blood: evidence for a direct transfer. Blood 2008; 111: 12081216.

[60] Sovershaev MA, Lind KF, Devold H, Jorgensen TO, Hansen JB, Osterud B, Egorina EM. No evidence for the presence of tissue factor in high-purity preparations of immunologically isolated eosinophils. J Thromb Haemost 2008; 6: 1742-1749.

[61] Engstad CS, Lia K, Rekdal O, Olsen JO, Osterud B. A novel biological effect of platelet factor 4 (PF4): enhancement of LPS-induced tissue factor activity in monocytes. . J Leuk Biol 1995; 58: 575-581. 